\title{
ENTRAPMENT OF CARBON DIOXIDE USING BAGASSE AND SODA LIME
}

\author{
Naineeka Singh Thakur, Shreyash Gholap, Mahipalsing Sisodiya, Vaibhav Gilbile, Aniruddh Bulbule \\ Department of Mechanical Engineering, ISB\&M SOT, \\ Pune, Maharashtra, India
}

\begin{abstract}
Post combustion absorption process is considered to be the best method for $\mathrm{CO}_{2}$ entrapment. Generally, various other kinds of absorbers are being used but also have restricted performance at industrial levels. Here we introduce a new material and methodology that can be used outdoor as well as indoor for absorbing $\mathrm{CO}_{2}$. The report describes the use of a new material for Direct Air Capture (DAC). The $\mathrm{CO}_{2}$ entrapment machine is useful for absorbing $\mathrm{CO}_{2}$ from the atmosphere and can be used at outdoor and indoor public areas too. The project work is based on the usage of bagasse filter washed with soda lime solution, and placed inside the portable machine structure. Bagasse being a waste material can thus be effectively utilized to serve the purpose. The test had been carried out at the PUC center wherein the air at the exhaust of the vehicle was examined; before the use of machine and after the use of machine. The observed reduction in $\mathrm{CO}_{2}$ in the air was $1.35 \%$. The short report provides an overview of working and effectiveness of the new filter.
\end{abstract}

Keywords - Carbon dioxide, soda lime, bagasse, sorbent, filter.

\section{INTRODUCTION}

According to the long-term studies, it is confirmed that the global climate change causing increase in mean temperature of Earth i.e. global warming owes to the anthropogenic $\mathrm{CO}_{2}$ emissions. As the ever-increasing energy demands of the population seems to be never-ending, $\mathrm{CO}_{2}$ emissions can't be controlled at a large extent. Due to this reason, capture of $\mathrm{CO} 2$ at the outlets of combustion sites proves to be a promising approach. Carbon dioxide capture technology was used for the first time in Europe and is widely renowned as Negative emissions technology (NET). There are three main $\mathrm{CO}_{2}$ capturing methods classified as 1) Pre-combustion 2) Postcombustion 3) Oxy-fuel combustion capture. In Precombustion fuel is pre-treated before combustion. This precombustion technology is being used in the Integrated Gasification Combined Cycle (IGCC) in which $\mathrm{CO}_{2}$ and $\mathrm{H}_{2}$ gases have to be first separated and $\mathrm{CO}_{2}$ is captured before $\mathrm{H}_{2}$ combustion. In Oxy-fuel combustion, oxygen gas instead of air is used for combustion so that less $\mathrm{CO}_{2}$ is released. Postcombustion is the process in which $\mathrm{CO}_{2}$ is removed after the release of flue gas. There are various methods under postcombustion capture. Andreoli et al.(2017) emphasize in their study in Missouri-Columbia states that a rubisco-inspired biometric approach enables reversible capture of $\mathrm{CO}_{2}$ from air. The study shows how $\mathrm{CO}_{2}$ can be captured spontaneously; to release $\mathrm{CO}_{2}$ entropy has to be decreased while temperature increases. In this technology, $\mathrm{CO}_{2}$ has to be released again towards storage site once it has been entrapped. [1,2] Dutcher et al.(2015) states that amine scrubbing is used to capture $\mathrm{CO}_{2}$ using aqueous amine solution. The scrubber is washed with aqueous amine solution and then the flue gas passes through it. Then the CO2-rich amine is sent to a stripper where its steamheating is done and $\mathrm{CO}_{2}$ is released. [3] Zarzycki and Leunga et al.(2017) state that the major processes of post-combustion are adsorption and absorption. Adsorption technology utilizes solid sorbents which allow physical and chemical binding of gas molecules on their surface. In the absorption method, a liquid solution of absorbent is used to entrap $\mathrm{CO}_{2}$ from the flue gas, which needs large surface area, pore structure, high selectivity towards $\mathrm{CO}_{2}$ and proper selection of sorbent. [4,5] Sanz-Pérez et al.(2016) in their study infer that large-scale $\mathrm{CO}_{2}$ absorption processes have been mainly using Monoethanolamine (MEA), Diethanolamine (DEA) and Methyl diethanolamine (MDEA). Despite their proven success, $\mathrm{CO}_{2}$ absorption by these amines is found to be energy consumptive. It imposes high Cost of Electricity (COE); and their major drawbacks are losses of amines and corrosive properties of amines. [6] Backer et al.(2008) analyzed and prepared a comparison between all these methods as shown in Table- 1. [7]

Selection of material and processes and utilization are a crucial part of a holistic approach for $\mathrm{CO}_{2}$ capture. Backus et al.(2010) states that the most widely used method today is the absorption by chemical solvents. The process of physical absorption is based on Henry's Law. Its characteristics are low energy expenditure, low cost and minimum effect on environment. The major advantage is it can be easily retrofit into existing plants. While the constituents of flue gas are nitrogen, carbon monoxide, oxygen, carbon dioxide is not the primary one. So, $\mathrm{CO}_{2}$ absorption has to be highly selective, and this is possible by the absorption method. [8]

Such Direct Air Capture (DAC) can be used at many locations and can be constructed and operated at industrial facilities. Sandalow et al.(2018) have reported that there are companies like 1) Carbon Engineering - using $\mathrm{KOH}$ with a slurry reactor including $\mathrm{Ca}(\mathrm{OH})_{2}$. 2) Climeworks - using amines. 3) Global Thermostat - using amine supported on porous ceramic structure. [9] Keith et al.(2018) in their analyzed work 


\section{International Journal of Engineering Applied Sciences and Technology, 2020 \\ Vol. 5, Issue 1, ISSN No. 2455-2143, Pages 619-622 \\ Published Online May 2020 in IJEAST (http://www.ijeast.com)}

addressed that these technologies sometimes use methods like amine systems for $\mathrm{CO}_{2}$ extraction and then $\mathrm{CO}_{2}$ regeneration from the sorbent where it has reacted with the chemicals to form precipitates. [10] In this report, the method is adopted in which $\mathrm{CO}_{2}$ is captured in the form of precipitate.

The absorptive membranes that have been used till date are expensive and have a complex polymeric structure. Khdary et al.(2020) represented a study on membrane capture used Polyvinylidene Fluoride-Hexafluoropropylene (PVDF-HFP) polymer which costs around INR 3,000 per membrane. This is the major limitation on using membranes. This report gives a synopsis on how a new membrane of bagasse has been used to hold the absorptive solvent to capture $\mathrm{CO}_{2}$. [11]

Table- 1 Maturity of $\mathrm{CO}_{2}$ capture methods

\begin{tabular}{|c|c|c|c|}
\hline $\begin{array}{c}\text { Capture } \\
\text { technology }\end{array}$ & Research & Demonstration & $\begin{array}{c}\text { Economically } \\
\text { feasible }\end{array}$ \\
\hline $\begin{array}{c}\text { Post- } \\
\text { combustion }\end{array}$ & $\checkmark$ & & $\checkmark$ \\
\hline $\begin{array}{c}\text { Pre- } \\
\text { combustion }\end{array}$ & $\checkmark$ & & $\checkmark$ \\
\hline $\begin{array}{c}\text { Oxy-fuel } \\
\text { combustion }\end{array}$ & $\checkmark$ & $\checkmark$ & \\
\hline
\end{tabular}

\section{PROPOSED AlgORITHM}

In the absorption process chemical or physical transfer of concentration of molecules from one phase to another. A membrane in this case is used which is classified under membrane absorption. It basically allows only $\mathrm{CO}_{2}$ to pass through with the layer usually made of composite polymer being a low-cost layer.

Wanga et al.(2011) has described that when membranes are used in gas absorption, they act as the contact between the gas and liquid solvent. Chemisorbents have proven to be much more effective for DAC processes than any other technology. [12]

\section{A. Chemical solvent and filter membrane used -}

Soda lime $(\mathrm{CaHNaO})$ - It is a granular mixture of calcium hydroxide along with sodium hydroxide or potassium hydroxide or both which is used to absorb $\mathrm{CO}_{2}$. Its composition is $\mathrm{Ca}(\mathrm{OH})_{2}(80 \%), \mathrm{H}_{2} \mathrm{O}(15 \%), \mathrm{NaOH}(15 \%), \mathrm{KOH}(<0.1 \%)$. It absorbs about $19 \%$ of its weight in $\mathrm{CO}_{2}$, thus $10 \mathrm{~g}$ of soda lime can absorb approx. 2.6L of $\mathrm{CO}_{2}$. Cost - INR 10 per packet of $50 \mathrm{~g}$.

Isa et al.(2012) addressed that soda lime was originally developed at Massachusetts Institute of Technology (MIT) by Prof. Robert E. Wilson to meet the need of an efficient absorbent which was to be used by soldiers in military gas masks to absorb $\mathrm{CO}_{2}$ exhaled by soldiers. [13]

Soda lime reacts with $\mathrm{CO}_{2}$ gas to form a stable solid precipitate which is retained in the membrane. To form a solution for the test, soda lime is dissolved in water.
Bagasse - Bagasse matrix is prepared from bagasse and is used as the membrane by washing it with soda lime. It can operate under all humidity levels and at high temperatures to play a role as the filter membrane. It can hold the soda lime solution effectively and is very cheap compared to various polymer structures and membranes used till date. While polymers cost around INR 3,000 per membrane, bagasse membrane can be made out of bagasse at just INR 4 per unit.

Porosity of matrix of bagasse membrane: Porosity is defined as the ratio of the amount (or volume) of voids in a rock to the total amount of the rock. It is expressed as a mathematical ratio as:

$$
P I=\frac{\text { Volume of voids }}{\text { Total volume of matrix }}
$$

Porosity Index gives an estimate to ensure that sufficient amount of flue gas can pass through the bagasse membrane.

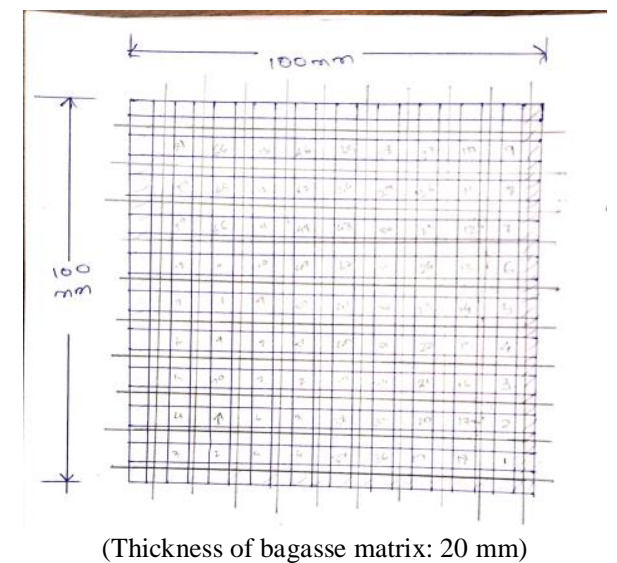

Fig. 1. Bagasse membrane matrix

Total volume of matrix $=$

$$
95 \mathrm{~mm} \text { X } 95 \mathrm{~mm} \mathrm{X} 5 \mathrm{~mm}=45.125 \times 10^{3} \mathrm{~mm}^{3}
$$

Hole dimensions $=5$ X $5=25 \mathrm{~mm}^{2}$

Number of holes $=81$ holes

Total volume $=5 \times 5 \times 5=125 \mathrm{~mm}^{3}$

Volume of void $=$ Total volume $\mathrm{X}$ number of holes

$$
\begin{aligned}
&=125 \times 81 \\
&=10.125 \times 10^{3} \mathrm{~mm}^{3} \\
& \text { Porosity Index }=\frac{\text { Volume of voids }}{\text { Total volume of matrix }} \times 100 \\
&=\left(10.125 \times 10^{3} / 45.125 \times 10^{3}\right) \times 100 \\
&=22.43 \%
\end{aligned}
$$

\section{B. Setup and reactions -}

In the design of carbon dioxide capturing equipment there are mainly two phases. Phase- 1 in which soda lime is sprayed and is held on bagasse matrix for absorption and Phase- 2 in which the filter is removed and replaced after all the soda lime in the bagasse membrane gets converted into precipitate after absorbing $\mathrm{CO}_{2}$. 


\section{International Journal of Engineering Applied Sciences and Technology, 2020 \\ Vol. 5, Issue 1, ISSN No. 2455-2143, Pages 619-622 \\ Published Online May 2020 in IJEAST (http://www.ijeast.com)}

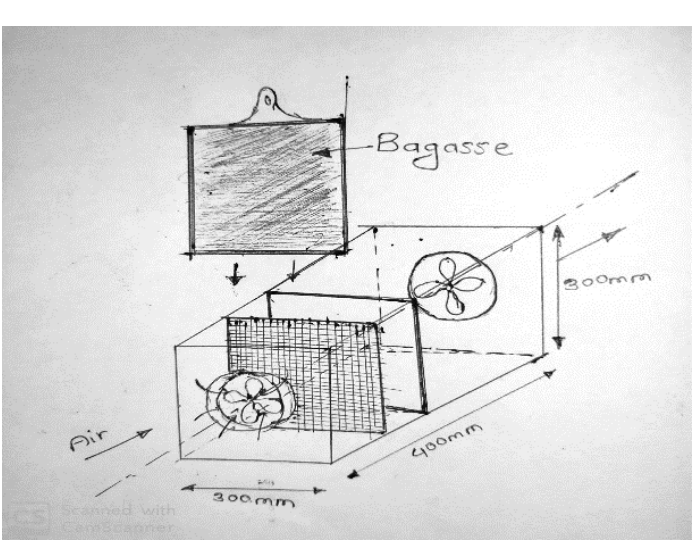

Fig. 2. Filter and compartment setup

The reactions between soda lime and $\mathrm{CO}_{2}$ are as follows:

1. $\mathrm{CO}_{2}+\mathrm{H}_{2} \mathrm{O} \rightarrow \mathrm{H}_{2} \mathrm{CO}_{3}$

2. $\mathrm{H}_{2} \mathrm{CO}_{3}+2 \mathrm{NaOH}($ or $\mathrm{KOH}) \rightarrow \mathrm{Na} 2 \mathrm{CO}_{3}\left(\right.$ or $\left.\mathrm{K}_{2} \mathrm{O}_{3}\right)+$ $2 \mathrm{H}_{2} \mathrm{O}+$ Heat

3. $\mathrm{Na}_{2} \mathrm{CO}_{3}\left(\right.$ or $\left.\mathrm{K}_{2} \mathrm{CO}_{3}\right)+\mathrm{Ca}(\mathrm{OH})_{2} \rightarrow \mathrm{CaCO}_{3}+2 \mathrm{NaOH}$ (or $\mathrm{KOH})$

First is the neutralization reaction that results into formation of carbonic acid from carbon dioxide and water. $\mathrm{Next}, \mathrm{NaOH}$ (and to a lesser limit $\mathrm{KOH}$ ) form sodium carbonate (or potassium carbonate) after reaction with carbonic acid. Calcium hydroxide reacts with these carbonates to form calcium carbonate which is an insoluble precipitate. Soda lime gets exhausted when all the hydroxides have become carbonates. This precipitate gets stacked up on the bagasse membrane.

\section{RESULT AND DisCUSSIONS}

Table -2 Test on bagasse membrane washed with soda lime solution

\begin{tabular}{|c|c|c|c|c|}
\hline Sample No. & Emissions & $\begin{array}{c}\text { Measured } \\
\text { value }\end{array}$ & Unit & Remark \\
\hline Sample 1 & $\mathrm{CO}$ & 0.437 & $\%$ & \multirow{5}{*}{$\begin{array}{l}\text { Reference } \\
\text { values }\end{array}$} \\
\hline \multirow[t]{4}{*}{$\begin{array}{l}\text { (Without } \\
\text { Filter) }\end{array}$} & $\begin{array}{c}\text { CO- } \\
\text { CORECTED }\end{array}$ & 0.437 & $\%$ & \\
\hline & HC & 558.0 & PPM & \\
\hline & $\mathrm{CO}_{2}$ & 5.18 & $\%$ & \\
\hline & $\mathrm{O}_{2}$ & 0.78 & $\%$ & \\
\hline Sample 2 & $\mathrm{CO}$ & 0.374 & $\%$ & TEST PASS \\
\hline \multirow[t]{4}{*}{$\begin{array}{l}\text { (With } \\
\text { filter) }\end{array}$} & $\begin{array}{c}\text { CO- } \\
\text { CORRECTED }\end{array}$ & 0.374 & $\%$ & \multirow[t]{4}{*}{$\begin{array}{c}(\mathbf{1 . 3 5 1 \%} \% \\
\text { reduction o } \\
\left.\mathrm{CO}_{2}\right)\end{array}$} \\
\hline & HC & 246.0 & PPM & \\
\hline & $\mathrm{CO}_{2}$ & 5.11 & $\%$ & \\
\hline & $\mathrm{O}_{2}$ & 0.63 & $\%$ & \\
\hline
\end{tabular}

\begin{tabular}{|c|c|c|c|c|}
\hline Sample 3 & CO & 0.245 & $\%$ & TEST PASS \\
\hline \multirow[t]{4}{*}{$\begin{array}{c}\text { (WITH } \\
\text { FILTER) }\end{array}$} & $\begin{array}{c}\text { CO- } \\
\text { CORRECTED }\end{array}$ & 0.245 & $\%$ & $\begin{array}{c}\mathbf{( 1 . 1 5 8 \%} \\
\text { reduction of } \\
\left.\mathrm{CO}_{2}\right)\end{array}$ \\
\hline & HC & 124.0 & PPM & \\
\hline & $\mathrm{CO}_{2}$ & 5.12 & $\%$ & \\
\hline & $\mathbf{O}_{2}$ & 0.72 & $\%$ & \\
\hline
\end{tabular}

Table 2 shows the experimental results obtained after the test conducted using the bagasse membrane washed with soda lime solution.

The amount of $\mathrm{CO}_{2}$ reduced in test 1 (sample 2):

$$
\begin{aligned}
& \frac{5.18-5.12}{5.18} \times 100 \\
& =1.158 \%
\end{aligned}
$$

The amount of $\mathrm{CO}_{2}$ reduced in test 2(sample 3):

$$
\begin{aligned}
& \frac{5.18-5.11}{5.18} \times 100 \\
& =1.351 \%
\end{aligned}
$$

The use of bagasse filter proves to be beneficial in terms that it is almost a waste material at many places and thus levies negligible expenses. It has a fairly good capability of holding the soda lime solution within its matrix structure. The soda lime solution is held on the bagasse matrix and absorbs ambient $\mathrm{CO}_{2}$ when the air comes in contact with it. The insoluble precipitate of carbonates gets stacked up on the bagasse membrane. This proposed bagasse matrix structure washed with soda lime solution is found to have ability to absorb $\mathrm{CO}_{2}$ from inlet air with a $\mathrm{CO}_{2}$ reduction percentage of $1.35 \%$.

\section{CONCLUSION}

Bagasse membrane has been successfully prepared and used for the test. Water was used to dissolve and prepare a solution of soda lime. The membrane porosity was maintained as per the proposed structure. The presence of soda lime showed excellent selectivity towards $\mathrm{CO}_{2}$ gas. The reaction left behind an insoluble precipitate of carbonates on the bagasse membrane. The bagasse membrane has successfully passed the test on $\mathrm{CO}_{2}$ entrapment. While this study demonstrates that the bagasse membrane successfully captures $\mathrm{CO}_{2}$ in the presence of soda lime solution, levying least cost, improvements will continue to be made and implemented due to large environmental potential they offer.

\section{ACKNOWLEDGEMENT}

It gives us great pleasure to present this report, a written testimony of this fruitful project that we have undergone. We whole-heartedly thank our college ISB\&M School of Technology and guide Prof. Aniruddha Bulbule for the needed support, facilities and cooperation during our project work. 


\section{International Journal of Engineering Applied Sciences and Technology, 2020 \\ Vol. 5, Issue 1, ISSN No. 2455-2143, Pages 619-622 \\ Published Online May 2020 in IJEAST (http://www.ijeast.com)}

\section{REFERENCE}

[1] Andreoli E. (2017). Materials and Processes for Carbon Dioxide Capture and Utilisation, College of Engineering, Swansea University, Swansea SA1 8EN, UK;

C 2017, 3, 16, DOI: 10.3390/c3020016 www.mdpi.com/journal/carbon

[2] Yu Cheng-Hsiu.; Tan Chung-Sung. (2012). A Review of $\mathrm{CO}_{2}$ Capture by Absorption and Adsorption, Article in Aerosol and Air Quality Research . October 2012 DOI: 10.4209/aaqr.2012.05.0132 https://www.researchgate.net/publication/268203019

[3] Dutcher B.; Fan M.; and Russell A. (2015). Amine-Based $\mathrm{CO}_{2}$ Capture Technology Development from the Beginning of 2013-A Review; American Chemical Society. DOI:10.1021/am507465f www.acsami.org

[4] Zarzycki R.; Panowski M. (2017). Analysis of the Flue Gas Preparation Process for the Purposes of Carbon Dioxide Separation Using the Adsorption Methods; J. Energy Resour. Technol. Mar 2018, 140(3): 032008, Paper No:JERT-16-1502 https://doi.org/10.1115/1.4038665

[5] Leunga D.; Caramannab G.; Maroto-Valer M. (2017). An overview of current status of carbon dioxide capture and storage technologies; Renewable and Sustainable Energy Reviews 39 (2014) 426-443; http://dx.doi.org/10.1016/j.rser. DOI:2014.07.093 13640321 www.elsevier.com/locate/rser

[6] Sanz-Pérez E.; Murdock C.; Didas S.; Jones C. (2016). Direct Capture of $\mathrm{CO}_{2}$ from Ambient Air; American
Shemical DOI:10.1021/acs.chemrev.6b00173 Chem. Rev. 2016, 116, 11840-11876; www.pubs.acs.org/CR

[7] Bakker S.; Coninck H.; and Groenenberg H. (2008). Carbon Capture and Storage; Energy research Centre of the Netherlands, www.breakingtheclimatedeadlock.com

[8] Backus W. (2010). Carbon Capture Technology-A Technoeconomic Evaluation of Absorption, Gasification, and Oxy-Coal Combustion for Coal Power Plants; https://engineering.wustl.edu/current-students/studentservices/ecc/Documents/Backus.pdf

[9] Sandalow D.; Friedmann J.; McCormick C.; McCoy S. (2018). Direct Air Capture Of Carbon Dioxide, (Katowice December 2018) Fifth Innovation for Cool Earth Forum $\begin{array}{lll}\text { (Tokyo October } & \text { 2018) } & \text { COP-24 }\end{array}$ https://www.osti.gov/servlets/purl/1460227

[10] Keith D.; Holmes G;; Angelo D.; Heidel K. (2018). A Process for Capturing $\mathrm{CO} 2$ from the Atmosphere, DOI: $10.1016 /$ j.joule.2018.05.006

[11] Khdary N.; Abdelsalam M.; and King Abdulaziz. (2020). Polymer-silica nanocomposite membranes for $\mathrm{CO}_{2}$ capturing; Arabian Journal of Chemistry 13, 557- 567; 1878-535 http://dx.doi.org/10.1016/j.arabjc.2017.06.001
[12] Wanga M.; Lawala A.; Stephenson P.; Sidders J.; Ramshawa C.; Yeunga H. (2011). Post-combustion $\mathrm{CO}_{2}$ Capture with Chemical Absorption: A State-of-the-art Review; Chemical Engineering Research and Design, Volume 89, Issue 9, September 2011, Pages 1609-1624. meihong.wang@cranfield.ac.uk

[13] Isa M.; Hassanuddin N. (2012). Characterisation of Carbon Dioxide Absorbent Material For Enclosed Space Applications; Article in Defence $\mathrm{S}$ and $\mathrm{T}$ Technical Bulletin $\quad$ April 2012 https://www.researchgate.net/publication/263284091 